\title{
Viabilitas Benih Jagung Lokal yang diberi Tepung Daun Tembelekan (Lantana camara Linn) dalam Pencegahan Serangan Sitophilus zeamais Motsch (Coleoptera:Curculionidae) Selama Penyimpanan
}

\section{Anna Tefa ${ }^{\mathrm{a}}$, Alexander Kehi Klau ${ }^{\mathrm{b}}$, dan Origenes Boy Kapitan ${ }^{\mathrm{c}}$}

${ }^{a}$ Fakultas Pertanian, Universitas Timor, Kefamenanu, TTU - NTT, Indonesia.email: annatefa@ roketmail.com

${ }^{b}$ Fakultas Pertanian, Universitas Timor, Kefamenanu, TTU - NTT, Indonesia.email: alexanderkehiklau@ gmail.com

${ }^{c}$ Fakultas Pertanian, Universitas Timor, Kefamenanu, TTU - NTT, Indonesia, email: boy57kapitan@ gmail.com

\section{Article Info}

\section{Article history:}

Article history:

Received 05 Januari 2019

Received in revised form 20 Januari 2019

Accepted 28 Januari 2019

DOI:

https://doi.org/10.32938/sc.v4i01.547

\section{Keywords}

Lantana Camara

Sitophilus Zeamai

Viabilitas Benih

\section{Abstrak}

Sitophilus zeamais Motsch (Coleoptera:Curculionidae) sering menyerang benih jagung selama periode penyimpanan sehingga dapa menurunkan viabilitas benih. Tembelekan (Lantana camara linn) memproduksi senyawa metabolit sekunder yang dapat berpera melindungi jagung dari gangguan Sitophilus zeamais. Tujuan penelitian ini adalah mencegah serangan hama Sitophilus zeamais dengan tepung daun tembelekan untuk meningkatkan viabilitas benih jagung selama penyimpanan. Penelitian ini menggunakan Rancangan Acak Lengkap (RAL) pola faktorial. Faktor pertama adalah takaran tepung tembelekan, yang terdiri dari empat level yakni $\mathrm{T}_{0}$ : tanpa tepung, $\mathrm{T}_{1}$ : $10 \% \mathrm{w} / \mathrm{w}, \mathrm{T}_{2}: 15 \% \mathrm{w} / \mathrm{w}, \mathrm{T}_{3}: 20 \% \mathrm{w} / \mathrm{w}$. Faktor kedua adalah lama kontak penyimpanan yang terdiri dari 3 level yakni $\mathrm{M}_{0}: 1 \mathrm{mingu}$, $\mathrm{M}_{1}$ : 2 minggu, dan $\mathrm{M}_{2}: 3$ minggu. Hasil penelitian menunjukkan bahwa interkasi perlakuan tepung daun tembelekan dan periode simpan mampu mempertahankan viabilitas dan vigor benih jagung lokal pada peubah potensi tumbuh maksimum 97,33\%, kecepatan tumbuh $19,06 \% / e t m a l$, indeks vigor $71 \%$ dan berat kering kecambah normal 5,4 gram.

\section{Pendahuluan}

Tanaman jagung (Zea mays, L) merupakan salah satu tanaman pokok yang kedudukannya sangat strategis setelah padi. Kebutuhan jagung dari tahun ke tahun terus mengalami peningkatan seiring berkembangnya industri pakan dan pangan. Berdasarkan data tahun 2016, produksi jagung Indonesia sekitar 23,58 juta ton atau meningkat 20,22\% dari produksi jagung tahun 2015 sebesar 19,61 juta ton, sedangkan produksi jagung di Propinsi Nusa Tenggara Timur (NTT) pada tahun 2016 sebesar 688,432 ton (Ditjen Tanaman Pangan, 2017).

Penggunaan benih bermutu tinggi merupakan unsur penting dalam peningkatan produksi tanaman. Menurut Arif dan Ratule (2015) penggunaan benih bermutu merupakan starter untuk mencapai produktivitas tinggi. Upaya peningkatan produksi jagung tidak terlepas dari kemampuan penyerapan teknologi produksi diantaranya adalah penggunaan benih bermutu yang bebas dari serangan hama. Serangan hama pada benih akan memberikan pengaruh yang sangat besar terhadap kualitas benih hingga pertumbuhan di lapangan (Yuniarti et al. 2015). Sitophilus zeamais adalah hama utama yang menyerang tanaman pangan diantaranya adalah jagung terutama di daerah tropis dan subtropis. Sitophilus zeamais berkembang biak pada biji jagung yang masih utuh sebelum dipanen maupun di gudang penyimpanan dengan meletakkan telur pada bij jagung. (Nonci dan Muis, 2015).

Tembelekan (Lantana camara linn) merupakan salah satu gulma potensial karena mempunyai kandungan bahan aktif yang berpotensi sebagai sumbe pestisida nabati bagi hama S. Zeamais. Hasil penelitian Astriani (2010) menunjukkan bahwa perlakuan pestisida nabati tembelekan pada benih jagung dengan dosis $6 \%$ mampu meningkatkan mortalitas S. zeamais pada hari kesampai -7 sebesar 57,5\%. Dosis tembelekan $2 \%$ mampu menekan penyusutan bobot benih $9,53 \%$. Dosis tembelekan $4 \%$ daya berkecambah benih $24,5 \%$, laju perkecambahan $3,20 \%$ serta bobot kering kecambah $1,27 \mathrm{~g}$. Penelitian in bertujuan mencegah serangan hama Sitophilus zeamais dengan tepung daun tembelekan untuk meningkatkan viabilitas benih jagung lokal selama penyimpanan.

\section{Metode}

Penelitian ini dilaksanakan di Laboratorium Fakultas Pertanian Universitas Timor pada bulan Juli sampai dengan Oktober 2018. Bahan yang digunakan adalah benih jagung lokal putih, daun tembelekan, kertas CD. Ala yang digunakan adalah blender, ayakan berukuran 50 mesh, stoples, germinator, timbangan analitik dan oven.

Penelitian ini menggunakan Rancangan Acak Lengkap (RAL) pola faktorial. Faktor pertama yang diujikan adalah takaran tepung tembelekan, yang terdiri atas empat level yaitu $\mathrm{T}_{0}$ : tanpa tepung, $\mathrm{T}_{1}: 10 \% \mathrm{w} / \mathrm{w}, \mathrm{T}_{2}: 15 \% \mathrm{w} / \mathrm{w}, \mathrm{T}_{3}$ : $20 \%$ w/w. Faktor kedua adalah periode simpan, terdiri atas 4 level yakni $\mathrm{M}_{1}$ : minggu, $\mathrm{M}_{2}$ : 2 minggu, dan $\mathrm{M}_{3}: 3$ minggu, $\mathrm{M}_{4:} 4$ minggu. Percobaan ini diulang 3 kali, masing-masing ulangan ditanam 25 butir benih. Data yang diperoleh dianalisis dengan program statistical analysis system (SAS). Perlakuan yang berpengaruh nyata diuji lanjut dengan duncan multiple range test (DMRT) taraf 5\% sesuai petunjuk Mattjik dan Sumertajaya (2006).

Daun tembelekan dikering anginkan selama \pm 2 minggu, dihaluskan menggunakan blender dan diayak menggunakan ayakan 50 mesh. Benih jagung dicampurkan dengan tepung tembelekan dengan dosis $10 \% \mathrm{w} / \mathrm{w}, 15 \% \mathrm{w} / \mathrm{w}$, dan $20 \%$ w/w dan disimpan sesuai perlakuan. Pengujian di Laboratorium menggunakan metode uji kertas digulung didirikan dalam plastik (UKDdP). Peubah viabilitas benih yang diamati yaitu:

\section{Potensi Tumbuh Maksimum (PTM) (\%)}

Potensi tumbuh maksimum diperoleh dengan menghitung jumlah kecambah yang tumbuh normal maupun abnormal pada 7 HST (hari setelah tanam). Potensi tumbuh maksimum dihitung dengan rumus:

$$
\operatorname{PTM}(\%)=\frac{\Sigma \text { benih yang tumbuh }}{\Sigma \text { benih yang ditanam }} \times 100 \%
$$

2. Daya Berkecambah (DB) $(\%)$

Daya berkecambah diperoleh dengan menghitung jumlah benih yang berkecambah normal pada 5 dan 7 HST. Daya berkecambah benih dihitung dengan rumus:

$$
D B(\%)=\frac{\sum K N \text { Hitungan } I+\sum K N \text { Hitung } I I}{\sum \text { benih yang ditanam }} \times 100
$$

Keterangan :

KN : Kecambah Normal

\section{Kecepatan Tumbuh $\left(\mathbf{K}_{\mathrm{CT}}\right)(\% /$ tetmal $)$}

Kecepatan tumbuh dihitung setiap hari selama 7 hari pada benih yang tumbuh normal. Kecepatan tumbuh dihitung dengan rumus:

$$
K C T=\left(\% \frac{K N}{\text { etmal }}\right)=\sum_{0}^{t n} \frac{N}{t}
$$

$$
\begin{array}{ll}
\text { Keterangan } & : \\
\mathrm{t} & : \text { waktu pengamatan ke- } \mathrm{i} \\
\mathrm{N} & : \text { persentase kecambah normal setiap waktu pengamatan } \\
\text { tn } & : \text { waktu akhir pengamatan (hari ke 7) } \\
1 \text { etmal } & \quad: 1 \text { Hari }
\end{array}
$$

\section{Berat Kering Kecambah Normal (BKKN) (g)}

Berat kering kecambah diperoleh dengan menimbang kecambah norma pada 7 HST yang telah dikeringkan di dalam oven bersuhu $60^{\circ} \mathrm{C}$ selama 72 jam.

\section{Indeks Vigor (IV) (\%)}

Pengamatan indeks vigor dilakukan terhadap jumlah kecambah normal pada hitungan pertama (first count) yaitu pada hari ke-5 (ISTA, 2010).

$$
\text { IV }(\%)=\frac{\sum \text { kecambah normal pada hitungan pertama }}{\sum \text { benih yang ditanam }} \times 100 \%
$$

\section{Hasil dan Pembahasan}

Hasil penelitian menunjukkan bahwa interaksi tepung daun tembelekan dan periode simpan meningkatkan potensi tumbuh maksimum pada benih yang diberi perlakuan tepung tembelekan $20 \%$ dan disimpan selama 1 minggu yaitu $97,3 \%$ dan pemberian tepung daun tembelekan $15 \%$ yang disimpan selama 4 minggu yaitu $96,0 \%$. Potensi tumbuh maksimum terendah terdapat pada perlakuan tepung daun tembelekan $20 \%$ yang disimpan selama 3 minggu yaitu $80 \%$ (Tabel 1). Daya berkecambah pada perlakuan tepung daun tembelekkan dan periode simpan memberikan hasil yang tidak berbeda nyata (Tabel 2).

Tabel 1. Interaksi Tepung Daun Tembelekan dan Periode Simpan Terhadap Potensi Tumbuh Maksimum (PTM) (\%) Benih Jagung Lokal Putih.

\begin{tabular}{lcccc}
\hline \multirow{2}{*}{ Takaran Tepung Tembelekan } & \multicolumn{4}{c}{ Periode Simpan (minggu) } \\
\cline { 2 - 5 } & 1 & 2 & 3 & 4 \\
\hline Tanpa Tepung & $96.00 \mathrm{a}$ & $93.33 \mathrm{ab}$ & $86.67 \mathrm{bc}$ & $92.00 \mathrm{ab}$ \\
Tepung 10\% & $93.33 \mathrm{ab}$ & $86.67 \mathrm{bc}$ & $90.67 \mathrm{ab}$ & $89.33 \mathrm{ab}$ \\
Tepung 15\% & $94.67 \mathrm{ab}$ & $86.67 \mathrm{bc}$ & $93.33 \mathrm{ab}$ & $96.00 \mathrm{a}$ \\
Tepung 20\% & $97.33 \mathrm{a}$ & $94.67 \mathrm{ab}$ & $80.00 \mathrm{c}$ & $89.33 \mathrm{ab}$ \\
\hline Keterangan : Angka yang diikuti huruf yang sama menunjukkan hasil yang
\end{tabular}

Keterangan: Angka yang diikuti huruf yang sama menunjukkan hasil yang tidak berbeda nyata berdasarkan DMRT pada $\square \square=5 \%$. 
Tabel 2. Interaksi Tepung Daun Tembelekan dan Periode Simpan Terhadap Daya Berkecambah (DB) (\%) Benih Jagung Lokal Putih

\begin{tabular}{lcccc}
\hline & \multicolumn{4}{c}{ Periode Simpan (minggu) } \\
\cline { 2 - 5 } Takaran Tepung Tembelekan & 1 & 2 & 3 & 4 \\
\hline TanpaTtepung & $93.33 \mathrm{a}$ & $97.33 \mathrm{a}$ & $90.67 \mathrm{a}$ & $93.33 \mathrm{a}$ \\
Tepung 10\% & $94.67 \mathrm{a}$ & $97.33 \mathrm{a}$ & $90.67 \mathrm{a}$ & $93.33 \mathrm{a}$ \\
Tepung 15\% & $97.33 \mathrm{a}$ & $96.00 \mathrm{a}$ & $96.00 \mathrm{a}$ & $92.00 \mathrm{a}$ \\
Tepung 20\% & $96.00 \mathrm{a}$ & $89.33 \mathrm{a}$ & $92.00 \mathrm{a}$ & $93.33 \mathrm{a}$ \\
\hline
\end{tabular}

Keterangan : Angka yang diikuti huruf yang sama menunjukkan hasil yang tidak berbeda nyata berdasarkan DMRT pada $\square \square=5 \%$.

Data analisis menunjukkan bahwa kecepatan tumbuh menunjukkan perbedaan yang tidak nyata dari semua perlakuan yang diuji kecuali pada perlakuan tepung tembelekan $2 \%$ pada periode simpan 2 minggu dengan kecepatan tumbuh yang lebih rendah dari perlakuan lainnya yaitu 15,77\%/etma (Tabel 3). Indeks vigor pada perlakuan tanpa tepung tembelekan pada periode simpan 2 minggu sebesar 45,33\% lebih rendah dibandingkan perlakuan lainnya (Tabel 4). Peubah berat kering kecambah normal tertinggi terdapat pada perlakuan tepung tembelekan pada periode 1 minggu penyimpanan yaitu sebesar $5,44 \mathrm{~g}$, berbeda nyata dengan perlakuan lainnya (Tabel 5).

Tabel 3. Interaksi Tepung Daun Tembelekan Dan Periode Simpan Terhadap Kecepatan Tumbuh (KcT) (\%/etmal) Benih Jagung Lokal Putih

\begin{tabular}{lcccc}
\hline \multirow{2}{*}{ Takaran Tepung Tembelekan } & \multicolumn{4}{c}{ Periode Simpan (minggu) } \\
\cline { 2 - 5 } & 1 & 2 & 3 & 4 \\
\hline Tanpa Tepung & $18.45 \mathrm{a}$ & $17.95 \mathrm{a}$ & $17.98 \mathrm{a}$ & $17.89 \mathrm{a}$ \\
Tepung 10\% & $18.50 \mathrm{a}$ & $17.59 \mathrm{a}$ & $18.72 \mathrm{a}$ & $17.43 \mathrm{ab}$ \\
Tepung 15\% & $18.58 \mathrm{a}$ & $17.79 \mathrm{a}$ & $19.06 \mathrm{a}$ & $18.77 \mathrm{a}$ \\
Tepung 20\% & $18.35 \mathrm{a}$ & $15.77 \mathrm{~b}$ & $17.98 \mathrm{a}$ & $17.98 \mathrm{a}$ \\
\hline
\end{tabular}

Keterangan : Angka yang diikuti huruf yang sama menunjukkan hasil yang tidak berbeda nyata berdasarkan DMRT pada $\square \square=5 \%$.

Tabel 4. Interaksi Tepung Daun Tembelekan dan Periode Simpan Terhadap Indeks Vigor (IV) (\%) Benih Jagung Lokal Putih

\begin{tabular}{lcccc}
\hline \multirow{2}{*}{ Takaran Tepung Tembelekan } & \multicolumn{4}{c}{ Periode Simpan (minggu) } \\
\cline { 2 - 5 } & 1 & 2 & 3 & 4 \\
\hline Tanpa Tepung & $69.33 \mathrm{a}$ & $45.33 \mathrm{~b}$ & $65.33 \mathrm{a}$ & $64.00 \mathrm{a}$ \\
Tepung 10\% & $64.00 \mathrm{a}$ & $64.00 \mathrm{a}$ & $72.00 \mathrm{a}$ & $58.67 \mathrm{ab}$ \\
Tepung 15\% & $69.33 \mathrm{a}$ & $62.67 \mathrm{a}$ & $72.00 \mathrm{a}$ & $70.67 \mathrm{a}$ \\
Tepung 20\% & $70.67 \mathrm{a}$ & $61.33 \mathrm{a}$ & $72.00 \mathrm{a}$ & $64.00 \mathrm{a}$ \\
\hline
\end{tabular}

Keterangan : Angka yang diikuti huruf yang sama menunjukkan hasil yang tidak berbeda nyata berdasarkan DMRT pada $\square \square=5 \%$

Tabel 5. Interaksi Tepung Daun Tembelekan dan Periode Simpan Terhadap Berat Kering Kecambah Normal (BKKN) (\%) Benih Jagung Lokal Putih

\begin{tabular}{lcccc}
\hline \multirow{2}{*}{ Takaran Tepung Tembelekan } & \multicolumn{4}{c}{ Periode Simpan (minggu) } \\
\cline { 2 - 5 } & 1 & 2 & 3 & 4 \\
\hline Tanpa Tepung & $5.36 \mathrm{ab}$ & $5.29 \mathrm{ab}$ & $5.15 \mathrm{ab}$ & $5.04 \mathrm{ab}$ \\
Tepung 10\% & $5.01 \mathrm{ab}$ & $4.86 \mathrm{abc}$ & $4.97 \mathrm{ab}$ & $4.34 \mathrm{c}$ \\
Tepung 15\% & $5.23 \mathrm{ab}$ & $4.82 \mathrm{bc}$ & $5.36 \mathrm{ab}$ & $4.97 \mathrm{ab}$ \\
Tepung 20\% & $5.44 \mathrm{a}$ & $4.87 \mathrm{abc}$ & $4.97 \mathrm{ab}$ & $4.82 \mathrm{bc}$ \\
\hline
\end{tabular}

Keterangan : Angka yang diikuti huruf yang sama menunjukkan hasil yang tidak berbeda nyata berdasarkan DMRT pada $\square \square=5 \%$.

Uji viabilitas benih pada peubah potensi tumbuh maksimum, kecepatan tumbuh, indeks vigor dan berat kering kecambah normal menunjukkan interaks nyata antara tepung daun tembelekan dan periode simpan. Benih yang diberi perlakuan tepung daun tembelekan mencegah terjadinya kerusakan benih karena cadangan makanan yang terdapat di dalam benih masih tersedia untuk proses perkecambahan. Peubah daya berkecambah menunjukkan data yang tidak berbeda nyata antara tepung daun tembelekan selama penyimpanan, namun daya berkecambah menunjukkan persentase yang tinggi yaitu diatas $90 \%$. Menurut Kuswanto (1997), perkecambahan adalah telah munculnya plumula, dan radikula dari embrio.

Umur benih jagung sangat dipengaruhi oleh sifat genetik maupun kondisi lingkungan simpan. Hasil penelitian ini menunjukkan bahwa benih jagung lokal yang digunakan untuk pengujian belum mengalami kemunduran yang signifikan setelah penyimpanan 4 minggu. Hal ini dilihat dari data potensi tumbuh maksimum mencapai $97,33 \%$, daya berkecambah $90 \%$, kecepatan tumbuh $19,06 \%$ /etmal, indeks vigor $72 \%$ dan berat kering kecambah normal 5,44 g. Karakter biji jagung lokal provinsi NTT yang paling utama adalah bijinya tahan disimpan lama, tahan terhadap hama bubuk, biji jagung bertekstur keras (Faesal dan Syuryawati, 2011) dan tahan terhadap cekaman kekeringan (Murningsih et al., 2015)

Benih jagung termasuk benih ortodoks yaitu benih yang dapat disimpan lama, dapat diturunkan kadar airnya dan dapat disimpan pada suhu rendah. Penyimpanan benih yang diberi perlakuan tepung daun tembelekan mampu mempertahankan viabilitas benih selama 4 minggu, sehingga penurunan awa kemunduran benih mungkin baru akan terjadi selama beberapa bulan penyimpanan. Menurut Copeland dan Mc Donald (2001), kemunduran benih tidak dapat dihentikan, tetapi hanya dapat diperhambat yaitu dengan mengendalikan faktor lingkungan pada penyimpanan agar kemunduran benih dapat ditekan semaksimal mungkin.

\section{Simpulan}

Penggunaan tepung tembelekan sangat diperlukan untuk mencegah serangan hama $S$. zeamays dan mampu mempertahankan viabilitas benih selama periode simpan 4 minggu. Benih jagung merupakan benih ortodoks yang ditandai dengan ciri tahan disimpan lama, dapat diturunkan kadar airnya dan dapat disimpan pada suhu rendah. Penurunan viabilitas benih akan berlangsung seiring berjalannya waktu karena benih bersifat irreversible

\section{Pustaka}

Astriani, D. 2010. Pemanfaatan gulma babadotan dan tembelekan dalam pengendalian Sitpohilus SPP pada benih jagung. Jurnal AgriSains. Vol. 1 No. 1. Hal. 56-67.

Arief R., dan Ratule, M.T. 2015. Strategi Penguatan Penangkaran Benih Jagung Berbasis Komunitas. Prosiding Seminar Nasional Serealia. Hal. 516-524.

Copeland. L.O. dan M.B. Mc. Donald. 2001. "Principles of Seed Science and Technology". Burgess Publishing Company. New York. $369 \mathrm{p}$.

Ditjen Tanaman Pangan. 2017. Komoditas Jagung Indonesia Siap Swasembada di Tahun 2017. Newsletter Pusdatin Pusat Data dan Sistem Informasi Pertanian. Vol. 14. No. 151.

Faesal dan Syuryawati. 2011. Urgensi Koleksi Plasmanutfah Jagung Lokal di Flores Nusa Tenggara Timur. Prosiding Seminar Nasional Serealia. Hal. 155-161.

International Seed Testing Association (ISTA). 2010. Seed Science and Technology. International rules for seed testing. Zurich: International Seed Testing Association.

Kuswanto, H. 1997. Analisis Benih. Andi, Yogyakarta. 140 hal.

Mattjik, A.A., Sumertajaya, I.M. 2006. Perancangan Percobaan. IPBPres; Bogor.

Murningsih T., Yulita, K. S., Bora, C.Y., Arsa, I. G. B. A. 2015. Respon Tanaman Jagung Varietas Lokal NTT Umur Sangat Genjah (Pena Tunu' Ana') terhadap Cekaman Kekeringan. Berita Biologi. Vol. 14. No. 1. Hal. 49-55.

Nonci, N., dan Muis, A. 2015. Biologi, Gejala Serangan dan Pengendalian Hama Bubuk Jagung Sitophilus zeamais Motschulsky (Coleoptera Curculionidae). Jurnal Litbang Pertanian. Vol. 34. No. 2. Hal 61-70.

Yuniarti, N., Suharti, T., Rustam, E. 2015. Identifikasi Hama dan penyakit benih nyamplung (Callophyllum inophyllum) di Carita, Ciamis, Cilacap, Purworejo, gunung Kidul, Alas purwo, Lombok dan pariaman. Prosiding Seminar nasional masyarakat biodiversifikasi Indonesia. Vol. 1 No. 6. hal. 1442-1447. 